\section{Light spectrum affects growth and gas exchange of common dandelion and purple coneflower seedlings}

\author{
Donato Castronuovo, Adriano Sofo, \\ Stella Lovelli, Vincenzo Candido, \\ Antonio Scopa \\ School of Agricultural, Forestry, Food \\ and Environmental Sciences (SAFE), \\ University of Basilicata, Potenza, Italy
}

\section{Abstract}

Artificial light, supplied by fluorescent lamps, has been effectively utilized in controlled-environment chambers for horticulture and floriculture nursery. This experiment aimed at investigating whether light-emitting diodes (LEDs) have the same effectiveness on plant morphology, photosynthetic and physiological responses as FLUORA lamps. Seedlings of common dandelion (Taraxacum officinale) and purple coneflower (Echinacea purpurea), species of high interest for their nutraceutical properties, were grown in controlled-environment chambers for 50 days under LED and FLUORA light sources as sole-source lighting systems, and the effects of artificial light supplies on plant photosynthetic performance and chlorophyll content (SPAD) were evaluated. The results were compared to plants grown under natural sunlight. In both species, total chlorophyll content (SPAD) values decreased for plants under sunlight, and for those grown under FLUORA lighting throughout the experimental period, while the values measured for plants grown under LEDs maintained a relatively constant value. At the end of the experiment, plant dry matter in both species was significantly lower under LEDs and FLUORA lighting, than the plants exposed to solar light. The two species showed different gas exchange dynamics under LEDs and FLUORA lighting, and photosynthetic performance decreasing after 10 days of light treatment compared to plants under sunlight. The results demonstrated that for common dandelion and purple coneflower photosynthetic processes are often modified when the species are cultivated under these artificial lighting and in controlled-environment chambers, because lamps do not able to generate the same spectrum and energy of sunlight.

\section{Introduction}

Living organisms are subjected to fluctuat- ing environmental conditions. While most animals are able to move away from unfavorable conditions, plants are sessile and so must cope with various types of environmental signals. Among these signals, light could be considered the most important. In addition to its key role in plant metabolism, where it drives photosynthetic processes, light energy also acts to regulate plant growth, development and morphology. Light is also a very versatile signal, which varies not only in quality, but also in quantity, duration and direction. In fact, light quantity, quality, direction, and diurnal and seasonal duration regulate processes from germination, through seedling establishment to the architecture of the mature plant and the transition to reproductive development. ${ }^{1}$

Artificial light, supplied by conventional lamps has been effectively utilized as solesource lighting systems in controlled-environment chambers for growing seedlings of many horticultural and floricultural species. ${ }^{1}$ Today, sustainable energy sources by efficient light sources or lighting systems are studied and applied to optimize plant growth and development in growing chambers. ${ }^{2}$ During the last years, the use of fluorescent light bulbs for plant growing in controlled-environment chambers has been substituted by more specific lamps, as FLUORA T8 Tubular fluorescent lamps (Osram, Munich, Germany), that provide nearly all the properties of sunlight for plant growing. ${ }^{2-4}$ FLUORA lamps, providing a specific lighting spectrum more suitable for plant growth, are more specific than the usual fluorescent lamps used for greenhouse lighting. ${ }^{3}$ Nevertheless, despite being efficient on the blue spectral region, they are weak in the critical red region. $^{2}$

Changing the supplementary light used in controlled-environment chambers from FLUORA to other lighting sources could even more reduce lighting costs as well as energy consumption, so contributing to a better environmental sustainability. In this context, energy efficient light sources as LEDs (light-emitting diodes) are able to emit light at specific wavelengths that improve photosynthetic rates and yield. ${ }^{4,5}$ In particular, LEDs emitting a light peak at $465 \mathrm{~nm}$ (blue color) and $630 \mathrm{~nm}$ (red color), that correspond to the absorption peaks of the main photosynthetic pigments, are the most useful for their ability of regulating plant photo-morphogenesis processes. In addition, LED lights have higher energy efficiency and longer lifetime than FLUORA. ${ }^{6}$

The two species studied were chosen due to their importance and usefulness for nutraceuticals purposes; in fact, common dandelion (Taraxacum officinale, Weber ex F.H. Wigg) and purple coneflower (Echinacea purpurea L.), belonging to the Asteraceae family, are known to be medicinal herbs. Common dandelion is a perennial herbaceous plant spread
Correspondence: Donato Castronuovo, School of Agricultural, Forestry, Food and Environmental Sciences (SAFE), University of Basilicata, Via dell'Ateneo Lucano 10, I-85100 Potenza, Italy. Tel.: +39.0971.205950 - Fax: +39.0971.205378. E-mail: donato.castronuovo@unibas.it.

Key words: Taraxacum officinale, Echinacea purpurea, LED, FLUORA, SPAD, dry matter.

Contributions: DC, plants culture and manuscript writing; ASo, laboratory setting; SL, morphometric analysis; $\mathrm{VC}$, statistical analysis; ASc, experimental plan.

Conflict of interest: the authors declare no potential conflict of interest.

Received for publication: 31 October 2015.

Revision received: 18 January 2016.

Accepted for publication: 18 January 2016.

This work is licensed under a Creative Commons Attribution-NonCommercial 4.0 International License (CC BY-NC 4.0).

(C) Copyright D. Castronuovo et al., 2016 Licensee PAGEPress srl, Italy

International Journal of Plant Biology 2016; 7:6281 doi:10.4081/pb.2016.6281

worldwide up to $2000 \mathrm{~m}$ a.s.l. and is considered sometimes as a weed. It has several healthpromoting effects, such as diuretic, laxative and tonic, and it is used against dyspepsia, anorexia and high levels of cholesterol. ${ }^{7}$ Purple coneflower is a perennial plant native of the prairies of Canada and the United States. This plant is well known as a medicinal plant for its effects in strengthening the immune system and for its antiviral activity. ${ }^{8,9}$

Fluorescence and LED lighting technology have been applied in horticulture to improve plant growth and development. ${ }^{10}$ On this basis, this experiment aimed at investigating whether LEDs have the same effectiveness on plant physiology as FLUORA lamps to grow seedlings of these two species in controlledenvironment chambers. Plants of both species were tested under three different light sources (environmental sunlight, LEDs and FLUORA), and the effects of different artificial light supplies on photosynthetic performance and chlorophyll content (SPAD) have been evaluated.

\section{Materials and Methods}

\section{Plant growth conditions}

Seeds of common dandelion and purple coneflower were sown in polypropylene plastic 
pots having a conical trunk shape $(12.0 \mathrm{~cm}$ high, $9.5 \mathrm{~cm}$ lower diameter, $14.0 \mathrm{~cm}$ upper diameter) and a volume of $1316 \mathrm{~cm}^{3}$. Pots were filled with a substrate (organic compost) added of an inorganic mineral base of perlite. Samples of the substrate were air dried at room temperature, and ground to pass a 2.0 $\mathrm{mm}$ mesh for the determination of physicalchemical parameters. All pots, until seeds germinate to produce three- to four-leaved seedlings, were kept in a glasshouse located in Potenza $\left(40^{\circ} \mathrm{N}, 15^{\circ} \mathrm{E} ; 730 \mathrm{~m}\right.$ a.s.l.) under environmental lighting at a constant temperature of $20^{\circ} \mathrm{C}$. The glasshouse, climatized by an automatic fanjet heating system and equipped with an automatic roof-opening device, was $28.0 \mathrm{~m}$ long and $11.0 \mathrm{~m}$ wide having a $3.8 \mathrm{~m}^{3}$ $\mathrm{m}^{-2}$ volume/surface index.

Compost $\mathrm{pH}$ values were measured using a pH meter (Jenway 4310, Barloworld Scientific T/As Jenway, Dunmow, Essex, England) on the substrate extract obtained by shaking the soil with double distilled water at 1:2.5 (w/v) substrate: water ratio. Substrate physico-chemical properties were the following: moisture content $=60.0 \% \quad(\mathrm{w} / \mathrm{w}), \mathrm{pH}=6.58$, total carbon $=34.0 \% \quad(\mathrm{w} / \mathrm{w})$, total organic nitrogen=2.14\% (w/w), C/N=14.17..$^{11,12}$ An optimum moisture content in the pots was guaranteed by watering when necessary.

\section{Light characteristics}

Different condition of irradiation quality were obtained using black chambers divided in single separated cabinets, respectively, and equipped with LEDs and FLUORA lamps, respectively. LEDs light source was aligned in a box $(32 \times 32 \times 4 \mathrm{~cm})$ with a combination of 225
( $5 \mathrm{~mm}$ ) LEDs $\times 65 \mathrm{~mW}$ (165 red and 60 blue) to form a light-emitting set. The box was assembled with a finned aluminum heat sinks fixed. FLUORA T8 32W/77 L Tubular lamps (Osram, Munich, Germany) were used for the fluorescent illumination. The right distance of plants from both light sources was adjusted to

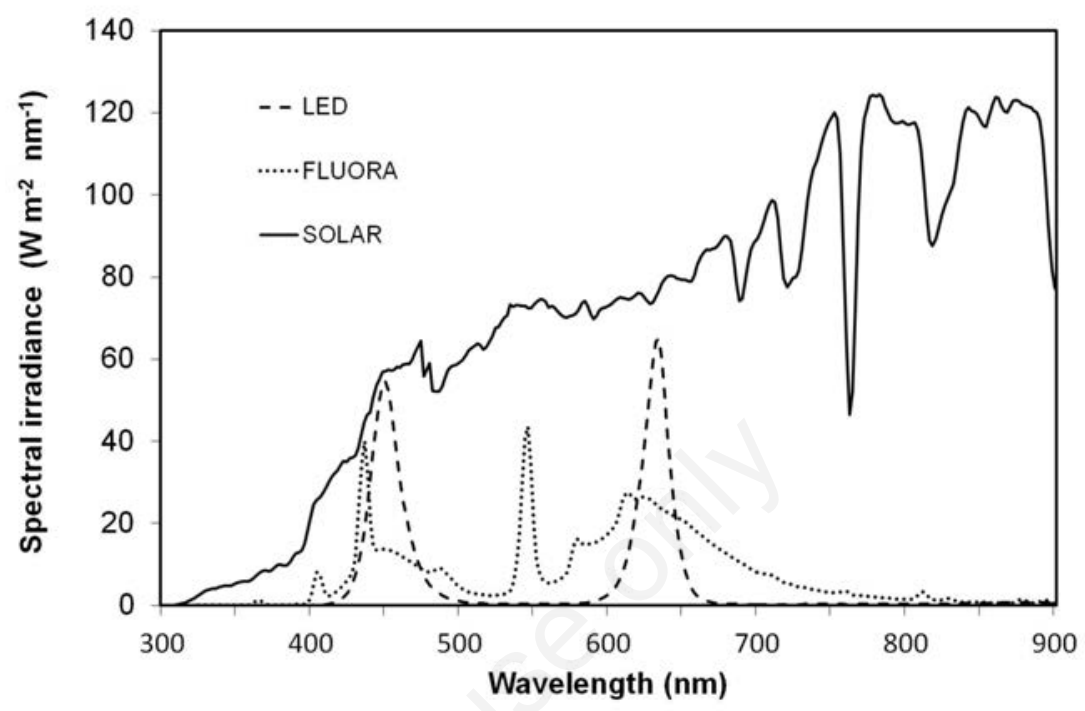

Figure 1. Mean radiation spectral distribution under light-emitting diodes (LED), FLUORA and solar light sources.

Table 1. Fresh weight, dry weight and dry matter content in common dandelion and purple coneflower seedlings grown under lightemitting diodes (LED), FLUORA and solar light sources after 50 days of light treatments.

\begin{tabular}{|c|c|c|c|}
\hline Light source & Fresh weight, g & Dry weight, g & Dry matter, $\%$ w/w \\
\hline \multicolumn{4}{|c|}{ Common dandelion } \\
\hline $\begin{array}{l}\text { LED } \\
\text { FLUORA } \\
\text { Solar }\end{array}$ & $\begin{array}{l}3.06 \pm 0.85^{\mathrm{b}} \\
5.06 \pm 0.79^{\mathrm{a}} \\
5.48 \pm 0.76^{\mathrm{a}}\end{array}$ & $\begin{array}{l}0.45 \pm 0.08^{c} \\
0.83 \pm 0.10^{b} \\
1.03 \pm 0.19^{a}\end{array}$ & $\begin{array}{l}15.05 \pm 2.14^{\mathrm{b}} \\
16.39 \pm 2.84^{\mathrm{b}} \\
18.50 \pm 4.02^{\mathrm{a}}\end{array}$ \\
\hline $\begin{array}{l}\text { Purple coneflor } \\
\text { LED } \\
\text { FLUORA } \\
\text { Solar }\end{array}$ & $\begin{array}{l}2.87 \pm 0.56^{\mathrm{b}} \\
3.95 \pm 0.55^{\mathrm{b}} \\
9.57 \pm 0.71^{\mathrm{a}}\end{array}$ & $\begin{array}{l}0.45 \pm 0.03^{\mathrm{b}} \\
0.60 \pm 0.10^{\mathrm{b}} \\
1.83 \pm 0.21^{\mathrm{a}}\end{array}$ & $\begin{array}{l}17.01 \pm 5.62^{\mathrm{a}} \\
15.33 \pm 2.09^{\mathrm{b}} \\
19.68 \pm 1.98^{\mathrm{a}}\end{array}$ \\
\hline
\end{tabular}

a,b,c Different letters in the same column denote significant differences among parameters.

Table 2. Net photosynthesis (A), transpiration (E), stomatal resistance (rs), and intercellular CO2 (Ci) in leaves of common dandelion and purple coneflower seedlings grown under light-emitting diodes (LED), FLUORA and solar light sources.

\begin{tabular}{|c|c|c|c|c|c|c|c|c|c|c|c|c|}
\hline \multirow[t]{2}{*}{ light source } & \multicolumn{4}{|c|}{0 days of light treatment } & \multicolumn{4}{|c|}{10 days of light treatment } & \multicolumn{4}{|c|}{50 days of light treatment } \\
\hline & $\begin{array}{c}\text { A } \\
\left(\mathrm{jumol} \mathrm{CO}_{2}\right. \\
\left.\mathrm{m}^{-1} \mathrm{~s}^{-1}\right)\end{array}$ & $\begin{array}{c}E \\
\left(\mathrm{mmol} \mathrm{H}_{2}\right. \\
\left.\mathrm{Om}^{-1} \mathrm{~s}^{-1}\right)\end{array}$ & $\begin{array}{c}r_{s} \\
\left(\sec c m^{-1}\right)\end{array}$ & $\begin{array}{c}\mathrm{C}_{i} \\
\left(\mathrm{\mu L} \mathrm{L}^{-1}\right)\end{array}$ & $\begin{array}{c}\mathrm{A} \\
\left(\mathrm{Hmol}_{\mathrm{CO}}\right. \\
\left.\mathrm{m}^{-1} \mathrm{~s}^{-1}\right)\end{array}$ & $\begin{array}{c}E \\
(\mathrm{mmol} \mathrm{H} \\
\left.0 \mathrm{~m}^{-1} \mathrm{~s}^{-1}\right)\end{array}$ & $\begin{array}{c}r_{s} \\
\left(\sec \mathrm{cm}^{-1}\right)\end{array}$ & $\begin{array}{c}\mathrm{C}_{i} \\
\left(\mu \mathrm{LL} \mathrm{L}^{-1}\right)\end{array}$ & $\begin{array}{c}\mathrm{A} \\
\left(\mathrm{mmol} \mathrm{CO}_{2}\right. \\
\left.\mathrm{m}^{-1} \mathrm{~s}^{-1}\right)\end{array}$ & $\begin{array}{c}E \\
\left(\mathrm{mmol} \mathrm{H}_{2}\right. \\
0 \mathrm{~m}^{-1}\end{array}$ & $\begin{array}{c}r_{\mathrm{s}} \\
\left(\sec \mathrm{cm}^{-1}\right)\end{array}$ & $\begin{array}{c}C_{i} \\
\left(\mu L^{-1}\right)\end{array}$ \\
\hline LED & $9.6 \pm 1.3^{\mathrm{a}}$ & $1.8 \pm 0.3^{\mathrm{a}}$ & $17.1 \pm 3 . .^{\mathrm{a}}$ & $325 \pm 13^{\mathrm{a}}$ & $1.5 \pm 0.4^{b}$ & $1.3 \pm 0.3^{\mathrm{a}}$ & $13.6 \pm 2.9^{\mathrm{a}}$ & $371 \pm 28^{\mathrm{a}}$ & $1.7 \pm 0.3^{\mathrm{a}}$ & $1.4 \pm 0.1^{\mathrm{a}}$ & $30.2 \pm 5.8^{b}$ & $314 \pm 34^{a}$ \\
\hline FLUORA & $8.4 \pm 2.1^{\mathrm{a}}$ & $2.5 \pm 0.7^{\mathrm{a}}$ & $10.4 \pm 2.0^{b}$ & $359 \pm 20^{b}$ & $1.1 \pm 0.3^{b}$ & $1.1 \pm 0.2^{\mathrm{a}}$ & $16.4 \pm 4.2^{b}$ & $390 \pm 28^{\mathrm{a}}$ & $2.2 \pm 0.6^{\mathrm{a}}$ & $0.8 \pm 0.1^{\mathrm{a}}$ & $494 \pm 6.3^{b}$ & $271 \pm 12^{b}$ \\
\hline Solar & $6.7 \pm 1.9^{b}$ & $1.4 \pm 0.8^{a}$ & $17.2 \pm 3.9^{\mathrm{a}}$ & $349 \pm 21^{c}$ & $6.1 \pm 1.1^{\mathrm{a}}$ & $0.7 \pm 0.0^{\mathrm{a}}$ & $14.0 \pm 3.8^{\mathrm{a}}$ & $150 \pm 23^{b}$ & $2.6 \pm 0.2^{\mathrm{a}}$ & $0.9 \pm 0.3^{\mathrm{a}}$ & $22.1 \pm 5.5^{\mathrm{a}}$ & $201 \pm 28 c$ \\
\hline Purple coneflower & & & & & & & & & & & & \\
\hline LED & $7.5 \pm 2.0^{\mathrm{a}}$ & $2.6 \pm 0.7^{\mathrm{a}}$ & $9.9 \pm 1.5^{b}$ & $393 \pm 38 b$ & $3.9 \pm 0.5^{c}$ & $1.1 \pm 0.2^{b}$ & $27.0 \pm 4.7^{\mathrm{a}}$ & $373 \pm 10^{\mathrm{a}}$ & $1.6 \pm 0.1^{\mathrm{a}}$ & $1.3 \pm 0.3^{\mathrm{a}}$ & $48.1 \pm 7.1^{\mathrm{a}}$ & $313 \pm 10^{\mathrm{a}}$ \\
\hline FLUORA & $7.8 \pm 1.4^{\mathrm{a}}$ & $2.8 \pm 0.7^{\mathrm{a}}$ & $9.3 \pm 1.0^{b}$ & $358 \pm 25^{\mathrm{a}}$ & $4.9 \pm 0.9^{b}$ & $3.2 \pm 0.3^{\mathrm{a}}$ & $4.9 \pm 0.8^{b}$ & $393 \pm 30^{\mathrm{a}}$ & $2.4 \pm 0.5^{\mathrm{a}}$ & $1.1 \pm 0.3^{\mathrm{a}}$ & $30.9 \pm 3.9^{b}$ & $311 \pm 20 \mathrm{a}$ \\
\hline Solar & $6.5 \pm 0.7^{b}$ & $2.5 \pm 0.3^{b}$ & $13.2 \pm 2.3^{\mathrm{a}}$ & $303 \pm 34^{a}$ & $5.4 \pm 1.0^{a}$ & $0.9 \pm 0.1^{b}$ & $20.9 \pm 5.5^{\mathrm{a}}$ & $319 \pm 13^{b}$ & $1.9 \pm 0.5^{\mathrm{a}}$ & $1.9 \pm 0.5^{\mathrm{a}}$ & $46.6 \pm 5.9^{\mathrm{a}}$ & $197 \pm 17^{\mathrm{b}}$ \\
\hline
\end{tabular}

Values are means \pm SD of ten measurements from ten different plants with ten independent replicates ( $\mathrm{n}=10)$ for each light treatment. For each column and light treatment, mean values followed by a different lower-case letter are significantly different at $\mathrm{P}=0.05$, according to Fisher's Least Significant Difference test. 
obtain equal conditions in terms of photosynthetically active radiation (PAR at leaf level $=800 \mu \mathrm{mol} \mathrm{m}{ }^{-2} \mathrm{~s}^{-1}$ ), also considering that LEDs have a higher luminous efficacy. Another group of plants was grown under sunlight in a climatized greenhouse located in Potenza (Southern Italy, $40^{\circ} 38^{\prime} \mathrm{N}, 15^{\circ} 48^{\prime} \mathrm{E}, 730 \mathrm{~m}$ a.s.l.). The spectra of the three different utilized light sources (LED, FLUORA and solar) were recorded using a LI-1800 spectroradiometer equipped with PC-1800 software (Li-Cor Inc., Lincoln, NE, USA).

\section{Light treatments}

Three- to four-leaved seedlings of both species were divided in three groups of ten units each: the plants of the first and second group were grown for 50 days into different black chambers under LEDs and FLUORA light, respectively, with a photoperiod of $16 / 8 \mathrm{~h}$ (light/dark) and at a constant temperature of $20^{\circ} \mathrm{C}$. The plants exposed to sunlight were put for 50 days in greenhouse under environmen- tal lighting at a constant temperature of $20^{\circ} \mathrm{C}$. The three- to four-leaved seedlings used at the beginning of the experiment were homogeneous in size and phenotypic characters. For each treatment, fresh and dry shoot weights were measured at the end of the experiment. The seedlings were weighted by an electronic balance before (fresh weight) and after being at $85^{\circ} \mathrm{C}$ until a constant dry weight was reached. Dry matter content was calculated from the dry weight/fresh weight ratio and expressed in percentage (w/w).

\section{Chlorophyll measurement}

Throughout the experiment, five measurements on the leaf areas were carried out with a chlorophyll meter SPAD-502 (Konica Minolta, Osaka, Japan) across the whole surface of leaves (on the same area for all data points). The mean values were calculated using the internal function of the chlorophyll meter and expressed in SPAD units. The correlation between total chlorophyll content and SPAD

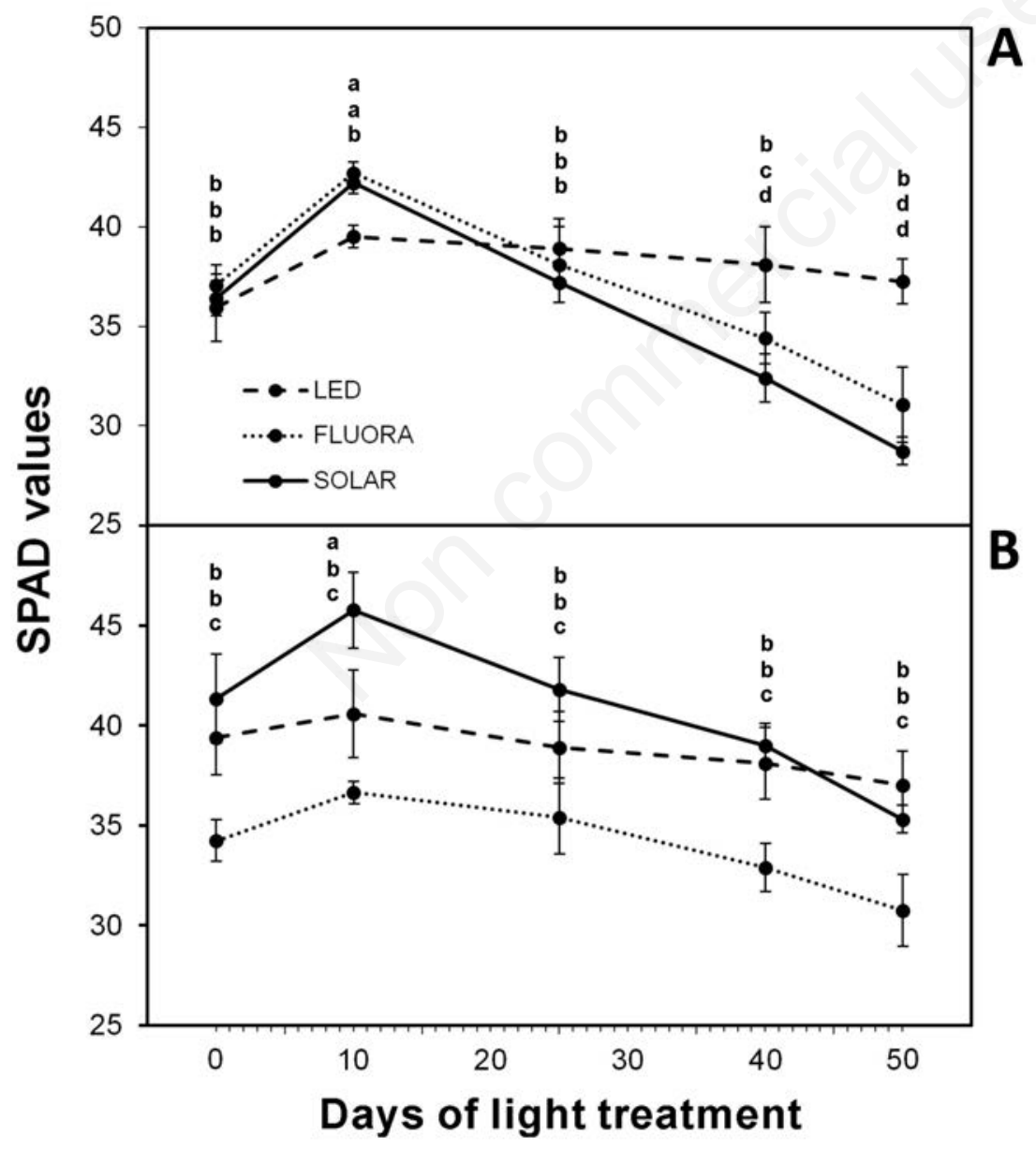

Figure 2. SPAD values in (A) common dandelion and (B) purple coneflower seedlings grown under light-emitting diodes (LED), FLUORA and solar light sources. Values are means of ten measurements on ten different plants $\left({ }_{ \pm} \mathrm{SD}\right)$ with ten independent replicates $(n=10)$. Mean values with a different lower-case letter are significantly different among light treatments at $\mathbf{P}=\mathbf{0 . 0 5}$, according to Fisher's Least Significant Difference test. has been verified in plants grown under environmental radiation. Indeed immediately after SPAD measurement, the same leaves were detached for the chlorophyll extraction in pure $\mathrm{N}, \mathrm{N}$-dimethylformamide (Sigma-Aldrich; Saint Louis, MI, USA) for $24 \mathrm{~h}$ in the dark. The absorbance of chlorophyll a and chlorophyll b were measured using a Jasco V-530 UVvis spectrophotometer (Tokyo, Japan) set at 649 and $665 \mathrm{~nm}$, respectively. ${ }^{13}$ The values of total chlorophyll $\left(\mathrm{Chl}_{\text {tot }}\right)$ were obtained by the sum of chlorophyll a and chlorophyll b content.

\section{Gas exchange}

At 0,10 and 50 days of light treatments, the measurements of net assimilation $(A)$, transpiration $(E)$, stomatal resistance $\left(r_{\mathrm{s}}\right)$ and intercellular $\mathrm{CO}_{2}$ concentration $\left(C_{\mathrm{i}}\right)$ were carried out on apical mature leaves, well exposed to radiation in ten plants representative of each experimental treatment. Measurements were carried out at 12:00-13:00 h using a programmable, open-flow gas exchange portable system (LI-6400, Li-Cor, Inc., Lincoln, NE, USA) operating at $500 \mu \mathrm{mol} \mathrm{s}{ }^{-1}$ flow rate.

\section{Statistical analysis}

The experimental design included three treatments arranged in a complete randomized block design with ten replicates $(n=10)$. Statistical analysis was performed by analysis of variance (ANOVA) with SAS software (SAS Institute, Cary, NC, USA). Fisher's Least Significant Difference (LSD) test was performed for the comparison of means at $\mathrm{P} \leq 0.05$.

\section{Results and Discussion}

The targeted spectral output of LEDs was more efficient for plant growth compared to FLUORA lamps relatively to the frequencies utilized in photosynthetic processes (Figure 1). Indeed, the numerical combination of red and blue LEDs allowed to obtain an optimal spectrum irradiative than FLUORA, with welldefined blue and red wavelengths. This result is of key importance, as plant blue light photoreceptors influence phototropism, stomata opening, leaf growth and chlorophyll production, while phytochromes absorb red light wavelengths, that initiate flowering, seed germination and root development. ${ }^{14,15}$ LEDs are used in numerous applications, including shelf-style lighting in growth rooms and in fullcycle plant production in greenhouses. ${ }^{2}$ These lights are also used to determine the better combinations of bulbs, usually of blue and red wavebands, able to produce optimal growth for different species. For both common dandelion and purple coneflower, a linear relationship between the observed parameters with high correlation coefficients was found between the 
measured values of $\mathrm{Chl}_{\text {tot }}$ and the values of the SPAD were found in plants grown under solar light. From the obtained data, the relationship between the two parameters was described by the following relations, where $\mathrm{x}$ indicates the value of SPAD:

$$
\begin{gathered}
\mathrm{Ch}_{\text {tot [purple coneflower] }}\left(\mathrm{g} \mathrm{cm}^{-2}\right)=0.550+0.794 \\
\mathrm{x}\left[\mathrm{R}^{2}=0.81\right] \\
\mathrm{Ch}_{\text {tot [common dandelion] }}\left(\mathrm{g} \mathrm{cm}^{-2}\right)=-25.713+1.469 \mathrm{x} \\
{\left[\mathrm{R}^{2}=0.80\right]}
\end{gathered}
$$

The values of the ratio $\mathrm{Chl} \mathrm{a} / \mathrm{b}$ in the observed range amounted to 3.35 and 3.04 for common dandelion and purple coneflower, respectively.

In common dandelion, SPAD values decreased for sun-exposed plants and for those grown under FLUORA lighting throughout the experimental period, while the values measured for plants grown under LEDs lighting maintained a relatively constant value (Figure 2A). A similar trend was observed for purple coneflower, where SPAD values in plants under sunlight were significantly higher compared to those of plants grown under FLUORA lights (Figure 2B). The SPAD values measured on purple coneflower plants grown under LEDs showed a constant trend similar to that found in common dandelion (Figure 2). At the end of the experiment, the shoot dry/fresh weight ratio was calculated (Table 1). In particular, dry weight/fresh weight ratio in both the species was significantly lower under LED and FLUORA lighting conditions than in plants under solar light (Table 1).

Values are means \pm SD of ten measurements from ten different plants with ten independent replicates $(n=10)$ for each light treatment. For each column and light treatment, mean values followed by a different lower-case letter are significantly different at $\mathrm{P}=0.05$, according to Fisher's LSD test. It is possible to enhance photosynthetic performance modifying the spectral energy distribution (light quality) of lamps. ${ }^{14}$ The imbalance in excitation of the photosystem I and II leads to a loss of quantum yield for $\mathrm{CO}_{2}$ fixation. ${ }^{6}$ In this research, common dandelion and purple coneflower showed different gas exchange dynamics under LED and FLUORA treatments, respectively. As regards to purple coneflower, after ten days of light treatment, $A$ declined more with LEDs lamps than with FLUORA lamps (3.9 and $4.9 \mu \mathrm{mol} \mathrm{CO}_{2} \mathrm{~m}^{-2} \mathrm{~s}^{-1}$, respectively) compared to plants grown under solar light (Table 2). FLUORA treatment significantly improved $E$, while $r_{\mathrm{s}}$ declined significantly (Table 2). However, $C_{\mathrm{i}}$ increased in both the treatments

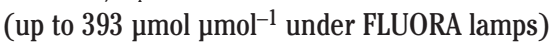
highlighting an effect of these two radiation types on the non-stomatal inhibition of photo- synthesis (Table 2). As regards to common dandelion, after ten days of light treatment, $A$ declined significantly by $78 \%$ respect to the solar while $E$ decreased (Table 2). The values of $r_{\mathrm{s}}$ and intercellular $\mathrm{CO}_{2}$ concentration $\left(C_{\mathrm{i}}\right)$ increased consequently (Table 2 ). The results indicate that, in both the plant species, irradiation treatments caused a stomatal and nonstomatal inhibition of photosynthesis respect to plants under solar light. After 50 day of light treatments, a deep reduction of all gas exchange parameters, likely due to leaf senescence, occurred (Table 2). Considering the importance and usefulness of both common dandelion and purple coneflower for nutraceutical purposes and for the extraction of bioactive molecules, this work was aimed at testing plant behavior under confined and controlled light conditions to avoid any interference with the open environment. The results obtained confirmed that, although the two species studied are of high interest for their nutraceutical properties, they do not grow well under the artificial light sources here used. For this reason, it could be very important to carry out morphological studies aimed to verify and explain the effects of large-spectrum lights on the growth of these species. In particular, in addition to $465 \mathrm{~nm}$ (blue) and $630 \mathrm{~nm}$ (red) wavelengths, large-spectrum LEDs sources could be tested for covering other wavelengths throughout the whole photosynthetically active region $(\mathrm{PAR}=400-700 \mathrm{~nm})$. In order to combine efficient photosynthesis and lighting strategies with new lamps types (LEDs and FLUORA) on plants, further studies on spectral impact on plant photosynthesis are thus necessary for determining the spectral energy distribution that better suits common dandelion and purple coneflower needs.

\section{Conclusions}

The obtained results demonstrated that photosynthetic processes are modified when both the species are cultivated under artificial lighting and in controlled-environment chambers, because the spectrum and energy of lamps are different from sunlight.

\section{References}

1. van Ieperen W. Plant morphological and developmental responses to light quality in a horticultural context. Acta Hortic 2012;956:131-9.

2. Darko E, Heydarizadeh P, Schoefs B, Sabzalian MR. Photosynthesis under artificial light: the shift in primary and secondary metabolism. Phil Trans R Soc B

\section{4;369:20130243.}

3. Poiré R, Wiese-Klinkenberg A, Parent B, et al. Diel time-courses of leaf growth in monocot and dicot species: endogenous rhythms and temperature effects. J Exp Bot 2010;61:1751-9.

4. Goto E. Plant production in a closed plant factory with artificial lighting. Acta Hortic 2012;956:37-49.

5. Yoshida H, Hikosaka S, Goto E, et al. Effects of light quality and light period on flowering of everbearing strawberry in a closed plant production system. Acta Hortic 2012;956:107-12.

6. Hogewoning SW, Trouwborst G, Engbers GJ, et al. Plant physiological acclimation to irradiation by light-emitting diodes (LEDs). Acta Hortic 2007;761:183-91.

7. Schütz K, Carle R, Schieber A. Taraxacum: a review on its phytochemical and pharmacological profile. J Ethnopharmacol 2006;107:313-23.

8. Sultan MT, Butt MS, Qayyum MM, Suleria HA. Immunity: plants as effective mediators. Crit Rev Food Sci 2014;54:1298-308.

9. Hudson JB. Applications of the phytomedicine echinacea purpurea (purple coneflower) in infectious diseases. J Biomed Biotechnol 2012;2012:769896.

10. Heo JW, Lee CW, Murthy HN, Paek KY. Influence of light quality and photoperiod on flowering of Cyclamen persicum Mill. cv. Dixie White. Plant Growth Regul 2003;40:7-10.

11. Nelson DW, Sommers LE. Total carbon, organic carbon and organic matter. In: Page AL, Miller RH, Keeney DR, eds. Methods of soil analysis. Part II. Madison: American Society of Agronomy-SSSA Publisher; 1982. pp. 539-79.

12. Bremner JM, Mulvaney CS. Nitrogen total. In: Page AL, Miller RH, Keeney DR, eds. Methods of soil analysis. Part II. Madison: American Society of Agronomy-SSSA Publisher; 1982. pp. 595-624.

13. Moran R. Formulae for determination of chlorophyllous pigments extracted with N,N-dimethylformamide. Plant Physiol 1982;69:1376-81.

14. Vanninen I, Pinto DM, Nissinen AI, et al. In the light of new greenhouse technologies: 1. Plant-mediated effects of artificial lighting on arthropods and tritrophic interactions. Ann Appl Biol 2010;157:393-414.

15. Moore JP, Paul ND, Jacobson RJ. A demonstration of the potential benefits of modification of light spectral quality in horticultural crops. Acta Hortic 2006;711:309-14. 